\title{
Correction to: Enhanced Multiple-Point Statistical Simulation with Backtracking, Forward Checking and Conflict-Directed Backjumping
}

\author{
Mohammad Shahraeeni $^{1}{ }_{(D)}$
}

Published online: 1 October 2018

(C) International Association for Mathematical Geosciences 2018

\section{Correction to: Math Geosci https://doi.org/10.1007/s11004-018-9761-y}

In the original version of this article, unfortunately Figure 9 was wrong due to a typesetting mistake.

The original article has been corrected.

The original article can be found online at https://doi.org/10.1007/s11004-018-9761-y.

$\triangle$ Mohammad Shahraeeni

s.shahraeeni@gmail.com

1 Geoscience Research Centre, TOTAL EP UK, Aberdeen, UK 